\title{
Female Collegiate Windmill Pitchers: INFLUENCES TO INJURY INCIDENCE
}

\author{
Jennifer L. Hitl, ${ }^{1}$ Brendan Humphrmes, ${ }^{1}$ Thomas Wemner, ${ }^{1}$ and Robert U. NeWton ${ }^{2}$ \\ 'Biomechanics Laboratory, Ball State University, Muncie, Indiana 47386; ${ }^{2}$ School of Biomedical and Sports \\ Sciences, Edith Cowan University, Perth, Western Australia.
}

\begin{abstract}
Hill, J.L., B. Humphries, T. Weidner, and R.U. Newton. Female collegiate windmill pitchers: Influences to injury incidence. J. Strength Cond. Res, 18(3):426-431.-Few studies have examined fast-pitch softball pitchers and associated injuries. The aim of this study was to investigate injuries occurring to collegiate softball pitchers and associated influential factors. A web-based survey of 181 Division I $(n=45)$, II $(n=30)$, and III $(n=54)$ collegiate softball pitchers was conducted. The survey involved self-reported data from the previous year that addressed (a) demographic information, (b) pitching and game data, (c) training program information, and (d) injury reporting. Demographic information, pitching and game data, and training program information were not statistically significant $(p<0.05)$ in relation to injury. Descriptive statistics were used to report totals and percentages of pitchers surveyed. Among 131 reported injuries, 36 were acute, 92 chronic/overuse, and 3 unspecified. Of the total injuries, 80 were directly from pitching, with 33 shoulder-related and 16 related to the lower back. Among injured pitchers, 109 took nonsteroidal anti-inflammatory drugs, 140 used modalities, 11 received surgeries, and 95 saw additional specialists. Pitchers are at a risk for injury, with $72.8 \%$ of surveyed pitchers being injured during the 2001-02 year.
\end{abstract}

KEX WorDS. shoulder, overuse, training

\section{INTRODUCTION}

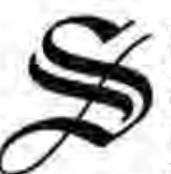

oftball first arose as a version of "indoor baseball" in 1887 and has matured into America's number 1 team sport played by over 40 million men and women $(11,14)$. Since 1972 when Title IX was passed, creating more collegiate teams and female athletic scholarships, along with the game reaching the Olympic level in 1996, young women have expressed a greater interest in softball. ${ }^{13} \mathrm{Al}$ though there has been a significant amount of research into injuries occurring in slow-pitch softball and related sports such as baseball, little has been reported concerning fast-pitch softball.

Although some anecdotal evidence and lay articles have reported softball pitching injuries, little scientific research has been published concerning the description and severity of the pitching injuries pitchers are suffering. The severity of injuries is broken down into acute and chronic/overuse injuries, with chronic injuries having a grading scale. The grade level of pitching injuries includes grade 1 = pain after activity; grade II = pain before and after the activity without decreasing performance; grade III = pain before, during, and after the activity that affects performance; and grade $\mathrm{IV}=$ intense pain that inhibits the athlete from playing. A study by Loosli et al. (7) found an $83 \%$ injury rate among a very small population $(N=24)$ of pitchers. Research by Barrentine et al. (3) found that forces on the shoulder and elbow in softball underhand pitching were around 70 $95 \%$ of the forces found in baseball overhand pitching. In addition, the torques placed on the shoulder and elbow in softball underhand pitching were the same or slightly greater in softball pitching vs. baseball pitching (3). Although slightly less than overhand pitching, underhand pitching was found to have an internal rotation velocity of over $4,000^{\circ}$ per second (3). A study by Maffet et al. (8) compared the muscle firing patterns in the shoulder and elbow between softball and baseball pitching. Despite the different styles of pitching, the researchers found that the pectoralis major muscle is the shoulder's power generator, the stabilization of anterior muscles resists against anterior forces, and the serratus anterior muscle plays a role in synchronization of the shoulder in both pitching styles (8). Several research studies examining ways to reduce injury during baseball pitching have been completed $(3,8)$. In contrast, softball pitchers have a similar risk for injury, yet they have not received the research attention to modify their training programs to reduce their injuries. Both Meyers et al. (9), along with the National Collegiate Athletic Association (NCAA; 12), reported fast-pitch softball injuries occurring to all players from all positions in the game. These 2 reports list pitchers being among the injured, but never clarify what specific injuries and in what conditions these injuries are developing among this group of athletes. In addition to injuries, Loosli et al. (7) found an $80-100 \%$ use of nonsteroidal anti-inflammatory drugs (NSAIDs) among pitchers with grade II and III injuries, which raises some concern that these pitchers may be taking NSAIDs for long periods of time. This long-term use may simply be masking the injury, allowing the pitcher to continue to play, and leading to an increase in injury severity.

Since softball has become competitive and the physical demands placed on pitchers have grown, there is a need for adjustments in pitchers' training and performance programs. Therefore, the purpose of this study was to investigate chronic/overuse injuries occurring to collegiate pitchers from NCAA Divisions I, II, and III. In addition to chronic/overuse injuries, acute injuries were also reported. This study investigated factors such as (a) demographic information, (b) pitching and game data, and (c) training program information that may influence the development of injuries. By investigating these factors associated with injury, this study will also report medical and rehabilitative measures pitchers have taken. By collecting injury and training program data, this study can provide insight into possible improvements for windmill pitching programs. 


\section{METHODS}

\section{Experimental Approach to the Problem}

The purpose of this study was to collect (a) demographic information, (b) pitching and game data, (c) training program information, and (d) an injury report on collegiate softball pitchers. A survey was designed using studies done by the NCAA (12), Loosli et al. (7), and other researchers in the field in order to prove the validity of the survey's context. To obtain valid data, survey information had to come from 1 source (the pitcher) because of the wide variety of information needed. The head coaches from each institution were the only other people to have access to the survey, and it is assumed that they, as professionals, would not provide false information. Therefore, it is assumed that all surveys were submitted by collegiate pitchers and filled out to the best of their knowledge. Although the pitcher is not a professional, she has the best understanding of the training and condition of her body. Thus, overuse injuries that may not be reported by an athletic trainer or physician might appear in this study. The goal of this study was to discover developing injuries and how to treat and prevent them before the injuries become too severe.

\section{Subjects}

Participants in this study were sophomore through senior female collegiate pitchers ranging from 18-26 years of age. Freshmen were not included in the study because information was reported from the previous collegiate year. The subject population represented all 3 NCAA Divisions (I, II, III) and all 4 regions (West, Midwest, East, South).

\section{Informed Consent}

Since this was a web-based survey, all participants read an E-mail explaining the study prior to participation. Pitchers were aware that their information was anonymous and could not be identified. Therefore, the pitchers' electronically submitted answers were considered consent approval for their participation in this study.

\section{Procedure}

After seeking Institutional Review Board for Human Subjects approval, surveys were sent to 775 out of 899 NCAA collegiate coaches from Divisions I, II, and III. From the NCAA list of colleges, surveys were sent to coaches with available E-mail addresses that were found in the National Fastpitch Coaches Association Directory and school web pages. Some E-mail addresses were unattainable. These college coaches who were attainable via E-mail were allowed to read an E-mail explaining the study, along with an attached link to the online survey. If these coaches were interested in having their pitching staff be a part of this study, it was asked that they forward the E-mail explaining the study and attached survey link to their returning pitching staff. If pitchers received the Email, they were asked to complete a web-based survey, which was managed by an online survey software system (InQsit, version 8.2.5, Ball State University, Muncie, IN).

Surveys examining self-reported pitching injuries and training from the previous year were collected from collegiate pitchers from all 4 regions (East, Midwest, West, and South) within the NCAA Divisions I, II, and III. Of the 181 total participants, 59 pitchers $(32.6 \%)$ were from
Division I, $42(23.2 \%)$ from Division II, and $78(43.1 \%)$ from Division III (2 unspecified). If each school has approximately 2 returning pitchers, and all of these pitchers received the survey, then the response rate would be $18 \%$ $(181 / 1,550)$. If all returning (sophomore-senior) collegiate pitchers from NCAA colleges are considered, then the subjects of this study represent $15.6 \%(281 / 1,798)$ of the total collegiate pitchers population.

The survey consisted of 4 sections:

- Demographio information: height, weight, dominant hand, and year in school;

- Pitching/game data: game and playing data self-reported from the previous year (2001-02), including how much the athlete pitches, the breakdown frequency of each pitch thrown, batting, and other positional play;

- Training program information: details of the periodization and style of the pitcher's basic strength and conditioning program from the previous year (2001-02); and

- Injury report: self-reported from the previous year (2001-02) and focused on all aspects of a pitcher's most severe injury. This portion included type of injury, anatomical location, how and when it happened, how much practice and game time missed, and therapy and pain reliever used. It was believed that the pitcher's understanding of her injury description was based on what her athletic trainer or team physician explained to her. Then, the severity grading scale of chronic injuries was described to the pitcher based on pain and ability to perform.

\section{Statistical Analyses}

Frequencies and percentages were calculated from the data. Pearson chi-square tests were run with cross-tabulations between injury and each factor (e.g., height, innings pitched, type of conditioning, etc.) concerning the pitcher's demographic information, pitching/game data, and training program information. An alpha level of $p \leq$ 0.05 was used as the criterion for statistical significance in all comparisons.

\section{Results}

\section{Demographic Information}

The demographic information included age, weight, height, dominant hand, and year in school. The age range of subjects was $18-26$, weight range $110-210$ pounds, and height range $5 \mathrm{ft} 0 \mathrm{in}$. to $6 \mathrm{ft} 2 \mathrm{in}$. From the 179 pitchers who specified, 164 pitchers were right-hand dominant. Pitchers included 68 sophomores, 55 juniors, 49 fourthyear seniors, and 9 fifth-year seniors.

Based on percentages, the injury rate was the highest among 20 - to 21-year-olds at $59.5 \%(N=78)$. Injury rate increased with body weight. Based on height, the lowest injury rate occurred in the range of $5 \mathrm{ft} 6 \mathrm{in}$. to $5 \mathrm{ft} 8 \mathrm{in}$. Dominant hand, years pitched, and current year in school were not related to injury incidence. Factors including height, weight, years pitched, dominant hand, and year in school were not significantly related to injury incidence.

\section{Pitching and Game Data}

Based on percentages from the pitching and game data, the fastball was related to the highest percentage of injury with $37 \%$ (48) of injured pitchers throwing the fast- 
TABLE 1. Acute injuries $(N=36)$ sophomore-senior collegiate pitchers experienced in 2001-02.

\begin{tabular}{|c|c|c|}
\hline Anatomic location & $N$ & Injury description \\
\hline Shoulder & 3 & $\begin{array}{l}\text { AC separation (2) (1-other) } \\
\text { Dislocation }\end{array}$ \\
\hline Pelvis, hips, groin & 3 & $\begin{array}{l}\text { Ligament sprain } \\
\text { Bursitis } \\
\text { Contusion }\end{array}$ \\
\hline Knee/patella & 6 & $\begin{array}{l}\text { Ligament sprain (3) (2-other) } \\
\text { Hyperextension (2) (1-sliding) } \\
\text { Bursitis (sliding) }\end{array}$ \\
\hline Ankle & 7 & Ligament sprain (7) (3-other, sliding) \\
\hline Forearm & 2 & $\begin{array}{l}\text { Ligament sprain } \\
\text { Fracture }\end{array}$ \\
\hline Wrist & 2 & $\begin{array}{l}\text { Ligament sprain (other) } \\
\text { Torn cartilage (other) }\end{array}$ \\
\hline Hand & 3 & $\begin{array}{l}\text { Ligament sprain (2-sliding, other) } \\
\text { Abrasion (sliding) }\end{array}$ \\
\hline Thumb/fingers & 3 & $\begin{array}{l}\text { Fracture (2) (1-hitting) } \\
\text { Contusion (other) }\end{array}$ \\
\hline Head/neck & 3 & Nerve injury (3-other) \\
\hline Lower back & 1 & Dislocation \\
\hline Lower leg & 1 & Contusion \\
\hline Foot/toes & 1 & Fracture (other) \\
\hline Internal organs & 1 & Internal injury (other) \\
\hline
\end{tabular}

ball as their dominant pitch. Of the injured pitchers, $39.7 \%$ (52) played another position (middle infield or outfield) that requires a considerable amount of throwing. Hitting (as a batter) was not considered to be a factor in injury. In addition, the success of pitchers based on number of wins was not associated with injury incidence. The dominant pitch thrown, positional play, hitting, and the pitcher's success rates were not related to injury.

\section{Training Program Information}

From the 179 pitchers who responded to the training portion of the survey, $69.8 \%$ (125) reported they do the same resistance training and conditioning program as the rest of their softball team. Among this $69.8 \%$ of the pitchers doing the same training as their team, $71.2 \%$ (89) were injured. Lack of stretching did not seem to be a factor in injury occurrence with $92.7 \%$ (164) of collegiate pitchers doing some form of stretching and $71.2 \%$ (126) doing both static (held stretch) and dynamic (movement stretch) stretching. Although it was not statistically significant in relation to injury, the most frequent strength equipment used was free weights with $88.9 \%$ (159), followed by strength training machines with $73.7 \%$ (132), bands with $38.5 \%(69)$, and other with $14.0 \%$ (25). The resistance training protocol followed by the majority of pitchers and their teams consisted of 5-8 exercises, $2-4$ sets per exercise, and $8-10$ repetitions per set. The reported condi- tioning among pitchers consists of $80.1 \%$ (141) agility/explosive, $78.4 \%$ (138) aerobic endurance, and $16.5 \%$ (29) swimming/water training.

There were no training factors that emerged as being significantly related to injury incidence.

\section{Injury Report}

Of the 180 pitchers who responded to the injury portion of the survey, $72.8 \%$ (131) reported being injured during the previous (2001-02) year. From the 131 pitchers suffering injury, $31.7 \%$ (57) of them had experienced more than 1 injury. When broken down by division, Division I had the highest injury percentage with $76.3 \%$ (45) of their pitchers experiencing injury, Division II following at $73.2 \%$ (30) within their division, and Division III with $69.2 \%(54)$. The injury percentage breakdown according to region was as follows: East had $77.4 \%$ (48) of their pitchers suffering injury; Midwest, $72.5 \%$ (58) within their region; South, $70.0 \%$ (16); and West, $60.0 \%$ (9). From the injuries reported, $61.1 \%(80)$ were directly caused from pitching; there were $29.8 \%$ (39) of injuries specified as other, and $1.5 \%(2)$ as onset that could be linked to pitching. The remaining $4.6 \%(6)$ of injuries were caused from sliding (5) or hitting (1). Of the total injuries, $58 \%$ (76) resulted in time lost from competition and training to recover. NSAID use was extremely high, ranging from $80 \%$ to $100 \%$ of injured pitchers reporting to be frequently taking these drugs.

\section{Acute Injuries}

Acute and chronic/overuse injuries were both collected with 36 acute, 92 chronic/overuse, and 3 unspecified. The description of reported acute injuries can be found in $\mathrm{Ta}$ ble 1 .

\section{Chronic/Overuse Injuries}

Since this study is primarily geared to determining chronic/overuse injuries, these chronic injuries were classified on a grading scale of severity, with 10 grade I injuries, 30 grade II, 39 grade III, and 13 grade IV. Of the 10 pitchers that experienced grade I injuries, the average number of innings they pitched throughout the previous season was 91 (Table 2). From the 30 grade II injuries, over half of these occurred in the shoulder and lower back (Table 3). Pitchers with grade II injuries averaged 87 innings pitched throughout the season. A high number of injuries (39) were classified as grade III, with over a third of them being shoulder related (Table 4 ). These pitchers averaged 82 innings pitched over the season. With regard to the 13 grade IV injuries, these pitchers threw an estimated 93 innings during their previous season (Table 5).

Table 2. Grade 1 chronic/overuse injuries $(N=10)$ sophomore-senior collegiate pitchers experienced in $2001-02$.

\begin{tabular}{|c|c|c|c|c|c|}
\hline $\begin{array}{l}\text { Anatomic } \\
\text { location }\end{array}$ & $N$ & Injury description & $\begin{array}{l}\text { Time took to } \\
\text { resolve injury (wk) }\end{array}$ & $\begin{array}{l}\text { Practice } \\
\text { lost (d) }\end{array}$ & $\begin{array}{l}\text { Games } \\
\text { missed }\end{array}$ \\
\hline Shoulder & 5 & $\begin{array}{l}\text { Inflammation } \\
\text { Muscle-tendon strain (3) (1-other) } \\
\text { Tendinitis (other) }\end{array}$ & $\begin{array}{l}3-4 \\
<1-2 \\
12-24\end{array}$ & $\begin{array}{c}0 \\
0-6 \\
1-6\end{array}$ & $\begin{array}{l}0 \\
0 \\
0\end{array}$ \\
\hline Elbow & 2 & Tendinitis (1-other) & $12-52$ & $0-6$ & 0 \\
\hline Wrist & 1 & Tendinitis (onset) & $5-6$ & $30-37$ & $1-2$ \\
\hline Lower back & 1 & Overuse & $5-6$ & 0 & 0 \\
\hline Ankle & 1 & Overuse & $1-2$ & 0 & 0 \\
\hline
\end{tabular}


TABLE 3. Grade 2 chronic/overuse injuries $(N=30)$ sophomore-senior collegiate pitchers experienced in $2001-02$.

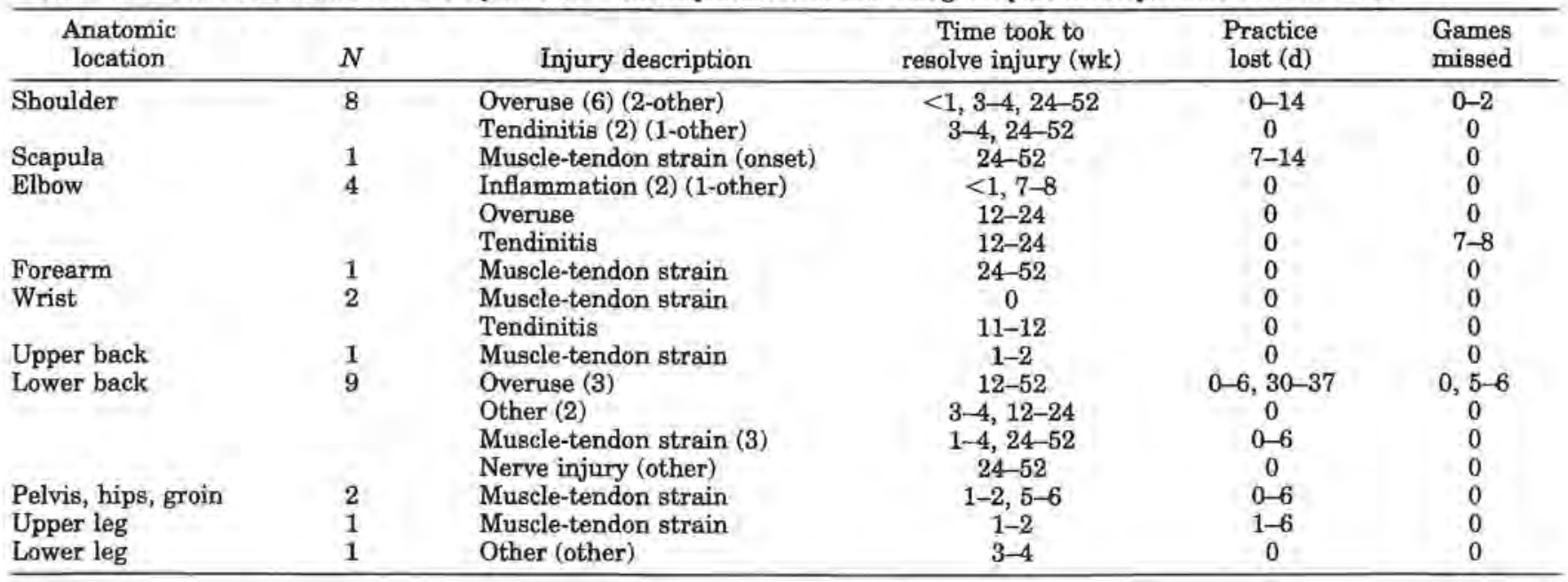

TABLE 4. Grade 3 chronic/overuse injuries $(N=39)$ sophomore-senior collegiate pitchers experienced in $2001-02$.

\begin{tabular}{|c|c|c|c|c|c|}
\hline Anatomic location & $N$ & Injury description & $\begin{array}{l}\text { Time took to } \\
\text { resolve injury (wk) }\end{array}$ & $\begin{array}{l}\text { Practice } \\
\text { lost (d) }\end{array}$ & $\begin{array}{l}\text { Games } \\
\text { missed }\end{array}$ \\
\hline \multirow[t]{6}{*}{ Shoulder } & 16 & Muscle-tendon strain (4) & $1-4,12-24$ & $0-6$ & $0-2$ \\
\hline & & Tendinitis (6) (2-other) & $1-4,9-10,12-24$ & $0-6,22-29$ & $0-4,13-14$ \\
\hline & & Overuse (2) & $3-4,12-24$ & 0 & 0 \\
\hline & & Bursitis & $<1$ & $1-6$ & 0 \\
\hline & & Nerve injury & $3-4$ & $1-6$ & $1-2$ \\
\hline & & Other (2) & $7-8,24-52$ & $15-21$, over 45 & $5-6,17-18$ \\
\hline \multirow{2}{*}{ Upper arm } & 3 & Tendinitis & 0 & 0 & 0 \\
\hline & & Muscle-tendon strain (2) & $1-2,7-8$ & $0-6$ & $0-2$ \\
\hline \multirow[t]{2}{*}{ Elbow } & 2 & Tendinitis & $12-24$ & Over 45 & 0 \\
\hline & & Hyperextension & $24-52$ & $1-6$ & $3-4$ \\
\hline \multirow[t]{2}{*}{ Wrist } & 2 & Tendinitis & $11-12$ & $11-6$ & $3-4$ \\
\hline & & Overuse & $24-52$ & $7-14$ & $3-4$ \\
\hline Hand & 1 & Inflammation & $24-52$ & 0 & 0 \\
\hline Thumb/fingers & 1 & Tendinitis & $24-52$ & 0 & 0 \\
\hline Head/neck & 1 & Inflammation & $1-2$ & $1-6$ & 0 \\
\hline Ribs & 1 & Stress fracture & $12-24$ & 0 & 0 \\
\hline Upper back & 2 & Muscle-tendon strain & $3-6$ & $0-6$ & $0-2$ \\
\hline \multirow[t]{3}{*}{ Lower back } & 4 & Inflammation & $3-4$ & $1-6$ & 0 \\
\hline & 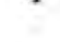 & Nerve injury (2) & $24-52$ & $0-6$ & 0 \\
\hline & & Other & $12-24$ & $15-21$ & $3-4$ \\
\hline Pelvis, hips, groin & 1 & Muscle-tendon strain & $12-24$ & $1-6$ & $3-4$ \\
\hline Knee/patella & $i$ & Overuse (other) & 0 & 0 & 0 \\
\hline Lower leg & 2 & Overuse (other) & $7-10$ & 0 & 0 \\
\hline Heel/Achilles tendon & 1 & Muscle-tendon strain & $24-52$ & $1-6$ & 0 \\
\hline Other & 1 & Muscle-tendon strain & $9-10$ & 0 & 0 \\
\hline
\end{tabular}

TaBLs 5. Grade 4 chronic/overuse injuries $(N=13)$ sophomore-senior collegiate pitchers experienced in $2001-02$.

\begin{tabular}{|c|c|c|c|c|c|}
\hline $\begin{array}{l}\text { Anatomic } \\
\text { location }\end{array}$ & $N$ & Injury description & $\begin{array}{l}\text { Time took to } \\
\text { resolve injury (wk) }\end{array}$ & $\begin{array}{l}\text { Practice } \\
\text { lost (d) }\end{array}$ & $\begin{array}{l}\text { Games } \\
\text { missed }\end{array}$ \\
\hline Shoulder & 4 & $\begin{array}{l}\text { Internal injury (other) } \\
\text { Hyperextension } \\
\text { Bursitis (2) }\end{array}$ & $\begin{array}{l}24-52 \\
24-52 \\
24-52\end{array}$ & $\begin{array}{l}\text { Over } 45 \\
\text { Over } 45 \\
\text { Over } 45\end{array}$ & $\begin{array}{c}5-6 \\
7-8 \\
3-4, \text { over } 28\end{array}$ \\
\hline Upper arm & 1 & Muscle-tendon strain & $1-2$ & 0 & $3-4$ \\
\hline Elbow & 1 & Nerve injury & $24-52$ & Over 45 & 0 \\
\hline Lower back & 2 & Other (other) & $11-12,24-52$ & $1-6,38-45$ & $3-4,15-16$ \\
\hline Pelvis, hips, groin & 1 & Muscle-tendon strain & $5-6$ & $30-37$ & $9-10$ \\
\hline Upper leg & 1 & Muscle-tendon strain (other) & $1-2$ & $7-14$ & 0 \\
\hline Lower leg & 1 & Stress fracture (other) & $5-6$ & $30-37$ & $21-22$ \\
\hline Ankle & 1 & Muscle-tendon strain (other) & $11-12$ & $30-37$ & $17-18$ \\
\hline Other & 1 & Muscle-tendon strain (other) & $24-52$ & $22-29$ & $3-4$ \\
\hline
\end{tabular}


From these chronic/overuse injuries, there were 60 associated with the upper extremity, with 33 involving the shoulder; 9 the elbow; 3 the wrist; and the rest distributed between the arm, hand, fingers, upper back, and ribs. From the 30 injuries associated with the lower trunk and extremities, 16 involved the lower back and 4 the pelvis/ hip/groin.

When considering total injuries, both acute and chronic, the most frequent time of year for injuries to occur appeared during the traditional season between March and May with $64.1 \%(84)$ injured. The remaining percentage of injuries occurred as follows: $20.6 \%$ (27) in December-February, $11.5 \%$ (15) in September-November, and $3.8 \%$ (5) in June-August. The majority, $53.8 \%(70)$, of injuries had developed from overuse, followed by $28.5 \%$ (37) occurring during practice, and $17.7 \%$ (23) during games. Dirt was the primary surface for injury incidence with $55.6 \%(70)$ of the injury total. Other injury rates of surfaces were $27.8 \%$ (35) of injuries on mondo/gym floor, $11.1 \%(14)$ on grass, and $5.6 \%(7)$ on artificial turf.

In addition to the description and condition of injuries collegiate pitchers are suffering, it is important to look at their treatment and rehabilitative techniques. NSAID use among the injured pitchers was $85.8 \%$ (109). Of the high percentage of NSAID use, $67.3 \%$ (74) of pitchers take it both before and after a game or practice, 20\% (22) take it just prior to practice or a game, and $12.7 \%$ (14) take NSAIDs just after practice or game. Muscle-tendon strains, tendinitis, and ligament sprains appear to be the injuries that most frequently require NSAIDs. From the other forms of treatment or rehabilitation, $73.8 \%$ (93) of injured pitchers were most frequently treated by cold packs or ice therapy. Thermo (heat) and electric (ultrasound, stimulation, etc.) therapy were utilized by $50 \%$ of respondents, with manual (massage) and taping/bracing accounting for a further $30 \%$. Approximately $15 \%$ of injured pitchers used an unspecified form of treatment. A total of $8.7 \%$ (11) of injured pitchers needed surgery. Of the injured pitchers, $42.4 \%$ (53) consulted with just their athletic trainer. In addition to consulting the athletic trainer, none consulted a biomechanist, $19.2 \%$ (24) consulted a physical therapist, $46.4 \%$ (58) consulted a doctor, and $10.4 \%$ (13) consulted other specialists.

Among all of the factors associated with injury incidence, days of practice lost and games missed in relation to grade level of injury were the only 2 factors that were statistically significant $(p<0.05)$.

\section{Discussion}

From the limited research completed on fast-pitch softball pitchers, it is evident that softball pitchers are suffering from numerous injuries (3, 7-9). In reference to the $72.8 \%$ of the surveyed population suffering injury, a projected 1,309 collegiate pitchers in the NCAA are suffering injuries yearly. However, in order to find ways to reduce or limit the number of injuries these pitchers are suffering, it is important to understand what specific types of injuries are occurring and in what training environment.

The demographic information recorded on pitchers was not significant in relation to injury. However, since it was stated in the literature that longer levers produce greater power and torque (11), factors such as height and weight could possibly make some pitchers more susceptible to injury. Evidence from the current research does not, however, support this view of increased height being a factor of injury.

The average number of innings pitched was not significant with injury incidence. The average innings pitched among pitchers with grade II and III injuries was less than those with grade I and IV injuries. This could be due to some pitchers having time-loss injuries, which do not allow them to throw as many innings. Just as Loosli et al. (7) found a decline in innings pitched with grade severity, this study showed that average estimated innings pitched is not directly associated with injury incidence.

Although there was a significant amount of overuse injuries caused from pitching, most injured pitchers had been hitting and playing other positions that place them at a high risk for acute injury. The NCAA (12) and Meyers et al. (9) suggest that hitting, base running, and overhand throwing can elevate the risk for injury,

According to the regional breakdown of total injuries, the warmer regions (West and South) had fewer injuries than the colder regions (Midwest and East). These results show that some colder climates could possibly create an environment that has a higher risk for injury development. When tight muscles try to perform in cold temperatures, they are more susceptible to muscle-tendon strains and pulls. Therefore, stretching should remain a large component of training. A reported 12 out of at least 159 pitchers that weight train do the same strength program as the rest of their team. This raises some concern because pitchers have entirely different movements than other position players. Therefore, they should consider using bands and other strength training exercises that are pitcher-specific, rather than all weights or lifting machines. Target areas to maintain muscle strength and joint stability would include rotator cuff and muscles around the shoulder region, the midsection such as the back and abdominals, and the pelvis/hip/groin region. Besides pitchers doing longer/aerobic endurance conditioning and some agility and explosive exercises, it may be beneficial if more pitchers did water workouts or cross training to relieve the volume of load placed on their joints. The training suggestions of keeping weight training position-specific, targeting muscles to prevent muscle imbalances and joint instability, and incorporating cross training into their workouts are in agreement with the literature $(1,2,4-6,10)$.

The target areas of concern appeared to be the shoulder with 33 and the lower back with 16 injuries. The source of most of these pitching-related injuries found is gradual onset overuse. In order to reduce the severity or grade of these injuries, restrictions may need to be made. Coaches and pitchers need to understand that a smaller number of quality pitches in practice are more beneficial in reducing overuse injuries than quantity of pitches. Pitchers who throw fewer pitches, but focus on proper technique and accuracy, gain more and remain healthier than the pitchers who throw high repetitions.

This study reported that a large number of pitchers with overuse injuries are frequently taking NSAIDs. Therefore, in agreement with Loosli et al. (7), this study raises a major concern as to whether or not these pitchers are using NSAIDs safely. There were 47 pitchers who appeared to take weeks to months to resolve an injury, but they did not miss any practice or games. Therefore, the long-term use of NSAIDs may not be helping the injury, 
but rather masking pain or providing a false sense of protection. By simply masking the pain or providing a false sense of protection, it allows the pitcher to continue to pitch and possibly increase the severity of the injury.

\section{Practical Applications}

With any sport, emphasis should be placed on seeking to prevent injury with a proper training program, rather than rehabilitation. The underlying causes of increased injury in fast-pitch softball pitching appear to be overtraining and not receiving position-specific training, as well as needing some cross training incorporated in the workouts. Although the risk of injury seems to be increasing for windmill softball pitchers, it is not a technique that needs to be outlawed. In comparison to baseball (overhand) pitching, research has found ways of preventative training. Softball pitching is now posing those same concerns, and ways to prevent or reduce injury need to be considered.

The following conclusions can be drawn from this research:

- Coaches and parents must focus on proper pitching technique and moderation at all levels of the game for young pitchers all the way to the elite levels.

- Strength coaches should design a pitcher's strength program in a way that is not just sports-specific, but position-specific as well. They should target muscle groups that will prevent muscle imbalances and enhance joint stability, such as rotator cuff and groin exercises.

- All coaches need to prevent overtraining by incorporating some cross training into their pitching programs. This cross training may include pool workouts, aerobic conditioning, biking, and other activities that help reduce some of the stress placed on the body during the pitching motion.

- Coaches and performance specialists need to begin to limit the number of pitches thrown over a week's time by incorporating light days that focus on wrist snaps and lower-body work, rather than throwing hard repetitions day after day.

- Athletic trainers and physicians should carefully monitor the NSAID use among pitchers. If this is done, pitchers will not be able to take NSAIDs just to mask their pain, allowing them to continue to play and cause further damage.

In addition to the few studies done by Loosli et al. (7), Meyers et al. (9), and the NCAA (12), this study has shown that softball pitchers in all 3 divisions and regions of the United States are at a high risk for injury, with $72.8 \%$ (131) of pitchers being injured among the 180 surveyed. Therefore, it is important for some preventative measures to be taken and further research to be performed in the area of chronic/overuse injuries occurring to collegiate softball pitchers.

\section{REFERENCES}

1. ARnheIm, D, AND W.E. Prentice. Principles of Athletic Training. 9 th ed. St. Louis, MO: McGraw-Hill, 1997.

2. BAECHLE, T. Essentials of Strength Training and Conditioning. Champaign, IL: Human Kinetics, 1994

3. BarRentine, S., G. Fleisig, J. Whiteside, R. Escamilla, AND J. ANDREWS. Biomechanics of windmill softball pitching with implications of injury mechanisms at the shoulder and elbow. Journal of Orthopaedic and Sports Physical Therapy. 28:405415. 1998.

4. BlOOMFIELD, J., T.R. ACKL.AND, AND B.C. ElliotT. Applied. Anatomy and Biomechanics in Sport. Cambridge: Blackwell Scientific, 1994.

5. Jarvinen, M. Muscle injuries. In: Clinical Practice of Sports Injury Prevention and Care. P.A.F.H. Renstrom, ed. Cambridge: Blackwell Scientific, 1994. pp. 115-121.

6. KEMPF, C. The Softball Pitching Edge. Champaign, IL: Human Kinetics, 2002.

7. Loosli, A., R. ReQUA, J, Garrick, AND E. HaNLEy. Injuries to pitchers in women's collegiate fast-pitch softball. Am. J. Sports. Med 20:35-37. 1992.

8. Maffet, M., F. Jobe, M. PinK, J. Brault, and W. MuthiyakOM. Shoulder muscle firing patterns during the windmill softball pitch. Am. J. Sports. Med. 25:369-374. 1997.

9. MeYers, M. B. Brown, AND J. BLoOM. Fast pitch softball injuries, Sports Med. 31:61-73. 2001.

10. Micheli, L, AND M. JenkTNS. The Sports Medicine Bible. New York: HarperCollins, 1995.

11. Monteleone, J., AND D. Crisfield, The Louisville Slugger Complete Book of Women's Fast-Pitch Softball. New York: Henry Holt, 1999.

12. National Collegiate Athletic Association. NCAA Injury surveillance system report. NCAA Injury Surveillance System 2001-02. 2002.

13. NuTr, A. Swinging for the fences. In: Nike Is a Goddess. L. Smith, ed. New York: Atlantic Monthly Press, 1998. pp. 33-54.

14. VAN WYK, K., J. REACH, AND B. SCHWARTZ. Softball Everyone. Winston-Salem, MA: Hunter Textbooks, 1989.

\section{Acknowledgments}

The authors gratefully acknowledge statistician James Jones and his colleagues for their assistance with the statistics of this study and Peter Gottwald for Inqsit suryey setup.

Address correspondence to Jennifer L. Hill, jenhill18@ hotmail.com. 